\title{
Economic Transition, Entrepreneurial Capacity, and Intergenerational Distribution
}

\author{
Svend E. Hougaard Jensen, Tobias N. Rasmussen \\ and Thomas F. Rutherford*
}

October 8, 2002

\begin{abstract}
A defining feature of transition economies is the expansion of the private sector. Motivated by the observation that new enterprises in transition economies seem to have a strong preference for recruiting young people, this paper studies intergenerational redistribution following from market reforms that stimulate private sector activity and firm creation. We implement a theoretical model and find that in some cases more than half of the current working age population may be made worse off by an increase in entrepreneurial capacity. This may help explain why market reforms have been voted down despite their long-run benefits.
\end{abstract}

JEL classifications: O11; O21; O31; O33; C68

Keywords: Transition economies; Structural reforms; Economic growth; Intergenerational distribution; Dynamic general equilibrium models

\footnotetext{
${ }^{*}$ We thank Oleh Havrylyshyn and Harry Trines for helpful comments and suggestions. Jensen: CEBR and University of Copenhagen; CEBR, Langelinie Allé 17, DK-2100 Copenhagen OE, Denmark; E-mail: shj@cebr.dk. Rasmussen: IMF and CEBR; IMF, 700 19th Street, N.W., Washington, D.C. 20431, USA; E-mail: trasmussen@imf.org. Rutherford: University of Colorado and CEBR; University of Colorado, Boulder, CO 80309, USA; E-mail: rutherford@colorado.edu. Opinions expressed are those of the authors, and should not be assumed to be those of our employers.
} 


\section{Introduction}

The introduction of free markets and extensions of property rights have provided the opportunity for greater entrepreneurial activity in former Soviet-type societies. In fact, the role of the private sector has already increased significantly. For example, Fischer and Sahay (2001) report evidence that the private sector share of GDP in transition economies has grown, on average, from about 25 percent in 1989-94 to about 50 percent in 1995-97. Although other factors may have contributed to the high output growth rates observed in most transition economies in recent years, advances in macroeconomic performance have undoubtedly been associated with higher rates of investment in new knowledge, skills and work processes within the private sector.

The growth-enhancing effects of market-oriented reforms would normally be regarded as desirable and therefore be welcomed by the general public. It is, however, widely believed that the transition process has had adverse distributional effects. This perception is broadly supported by available evidence on the changes in the individual distribution of incomes and consumption possibilities in transition economies. Indeed, the conventional wisdom is that the transition process has implied a marked increase in inequality and poverty; see, e.g., Aghion and Commander (1999). ${ }^{1}$ Thus, the fact that the reform process has been held back in most transition economies may be given a political economy interpretation: too many groups in society have not benefited from the reforms and have therefore voted against them.

This paper studies distributional aspects associated with economic transition. However, rather than approaching this from the perspective of different socioeconomic groups ("rich vs. poor"), our focus is on the intergenerational aspects ("young vs. old"). This dimension has, to our knowledge, been subject of little academic attention so far. Our motivation for addressing this issue is mainly based on the following two characteristics of the transition process: First, new enterprises have a strong preference for recruiting young people, and, second, new enterprises pay better salaries than old enterprises. Antila and Ylöstalo (1999) present detailed evidence of both stylized facts from the

\footnotetext{
${ }^{1}$ This may not generally be the case, however. For example, Keane and Prasad (2002) report evidence that while inequality in labor earnings rose markedly and consistently during 1990-97, income and consumption inequality declined in 1990-92 and rose only moderately above pre-transition levels by 1997 .
} 
Baltic states in 1998: In Lithuania, for example, of those aged 30 and below, 44 percent worked in new enterprises, whereas this was only the case 17 percent of those aged 50 and above. Similarly, in Estonia the average monthly salary of workers in new enterprises was found to be about 30 percent higher than the salary of workers in old enterprises. These numbers suggest that the young have benefited disproportionately from the creation of new private sector enterprises.

There may be several reasons why old workers are less likely than young workers to be employed in a new enterprise. One possibility is that the young are simply endowed with skills that are most demanded in the process of firm creation. Or it may be that people have to acquire these skills, and that the cost/benefit trade-off of this investment is more favorable to the young. For example, Friedberg (2002) finds strong evidence in support of forward-looking factors in the decision to acquire computer skills: the number of years to retirement is shown to be an important determinant, which indicates that fixed costs play a role in skill acquisition. Acquisition of the "entrepreneurial skills" that are valuable in new firms may involve a similar element of fixed costs, which would make it less worthwhile for those with few years to retirement.

Against that background, the objective of this paper is to formalize the linkages between economic transition and intergenerational welfare redistribution. Thereby, we should be in a better position to understand why the different generational groups would, or would not, be likely to support the ongoing reform process. For that purpose we develop a model with overlapping generations (OLG) and endogenous technological change through expanding product varieties. New firms are created as a result of investments that rely on the input of entrepreneurial skills. Thus, it is entrepreneurial activity that drives economic growth. ${ }^{2}$ The increase in innovative capability associated with opening of the economy is modeled as an exogenous increase in household endowments of entrepreneurial skills. While we make various assumptions about which generations stand to gain from an increase in entrepreneurial possibilities, our base case reflects the empirical evidence from the Baltics as alluded

\footnotetext{
${ }^{2}$ That entrepreneurs play a crucial role for economic growth in transition economies is strongly indicated by McMillan and Woodruff (2002) who argue that "the success or failure of a transition economy can be traced in large part to the performance of its entrepreneurs" (p. 154).
} 
to above. The central point here is that it seems reasonable to assume that the young are more responsible for the surge in innovative capacity than are the old.

Our model has some similarities with the model used by Fougère and Mérette (2000) to look at issues relating to population ageing. A central difference is that while their endogenous growth mechanism relies on human capital accumulation, ours relies on firm creation. The process of endogenous technological change is important here for several reasons. First, it is capable of generating the large increase in growth rates that have been observed in some transition economies. In our model endowments of entrepreneurial skills constitute a small but fixed share of long-run output and a small increase in the level of these endowments may therefore have substantial effects on the overall economy. ${ }^{3}$ Second, in combination with the OLG framework, the formulation of age-dependent levels of entrepreneurial skills can capture the idea that it is the young and future generations that generate the higher output level-and receive the awards from doing so. Finally, the assumption that a long-run increase in productivity is dependent on skill sets that are only fully available among young and future generations is consistent with the fact that many transition economies have been slow to realize the high growth rates that were predicted for them.

Our analysis generates several interesting results. Overall, we find that an increase in entrepreneurial capacity causes not only a surge in economic activity, but also a redistribution in favor of future generations. While it is well-known that a transition to a higher income level may involve an initial period of rising inequality, we show that such a transition may in fact imply an absolute reduction in the welfare of older generations. Unless it is fully offset by an immediate jump in investments, an increase in entrepreneurial capacity will tend to be associated with a reduction in the unit price of entrepreneurial skills and a rise in interest rates. The current old thus suffer from a higher relative price of consumption and experience capital losses on existing assets, but do not live long enough to gain from future increases in productivity. International

\footnotetext{
${ }^{3}$ This issue is related to the discussion of the determinants of the magnitude of the effects of trade liberalization. A standard model with constant returns to scale predicts effects that are much smaller than is generally thought to be the case. Consequently, several authors, including Rutherford and Tarr (2002), have proposed models for evaluating the effects of trade liberalization that operate with increasing returns to scale.
} 
capital markets are important for this outcome, as they influence the extent to which higher investments can be financed without affecting domestic prices and interest rates. Thus, with imperfect international capital markets we find it possible for a majority of current generations to experience an absolute welfare loss. ${ }^{4}$ From a political economy perspective this is an important insight, as it offers a plausible explanation for the reluctance to embrace reform agendas in transition economies.

From here the paper proceeds in two main parts. Section 2 presents the model in detail, including a characterization of the steady state and an outline of the calibration method. Section 3 then offers an analysis of the effects of an increase in entrepreneurial capacity, including a discussion of the role of capital mobility and other kinds of sensitivity analysis. Section 4 concludes.

\section{The model}

We work with an overlapping generations model in which economic growth is due to expanding product varieties. In this model, the development of new product varieties relies on the use of entrepreneurial skills. In later sections of the paper we use the model to look at the intergenerational effects of an exogenous increase in entrepreneurial skills, reflecting the introduction of entrepreneur-driven capitalism that characterizes transition economies and is associated with a process of converging to a higher income level. The model is deterministic and consumers and firms have perfect foresight, so investment decisions are determined by the time paths of future prices. Final goods are produced using intermediate inputs, are traded on world markets, and, without restrictions on the trade balance, a small open economy assumption means that the price is given from abroad. Firms producing intermediate inputs have a monopoly on their particular variety, and new firms enter if the present value

\footnotetext{
${ }^{4}$ Our results rely on a formulation in which households only care about their own lifetime consumption. If, alternatively, generations are altruistically linked consumption losses experienced by the old would be compensated by the gains expected for future generations. Studies of the advanced economies tend to find little or no evidence that such intergenerational links play an important role, see, e.g., Altonji, Hayashi and Kotlikoff $(1992,1997)$. This possibility may nevertheless play a part in explaining the willingness of older generations to suffer the adverse distributional effects of the transition process. If so, our results may be interpreted as the direct effect on individual welfare excluding altruism.
} 
of markup revenue, equal to the value of the firm, covers the cost of developing a new firm.

Investments in firm creation produce "blueprints" where this term should be interpreted broadly as the result of any kind of profit-driven activity that develops new knowledge. Examples are inventions of new products or, more generally, anything that contributes to a more productive business environment while also generating income for the developer. The number of intermediate firms in the economy can therefore be interpreted as an index of productive knowledge. Similarly, the value of these "blueprints"-in our model equal to the market value of firms producing intermediates-is akin to the concept of knowledge capital. The focus of this paper is firm creation taking place within transition economies and not the mere application of inventions developed abroad. ${ }^{5}$ We therefore assume that there is no international market for blueprints or intermediate inputs in the model. This is reasonable given the broad interpretation of a blueprint applied here, as there are important non-tradable elements in what constitutes a productive business environment. Further, it is, arguably, exactly the unleashing of the capacity to apply existing human capital more productively that best characterizes transition economies.

The production side of the model builds on the endogenous growth framework originating in Romer (1987) and subsequently developed in, e.g., Romer (1990) and Barro and Sala-i-Martin (1996, ch. 6). An important difference from the standard endogenous growth framework, however, is the presence of entrepreneurial skills as an input in the production of blueprints for new firms. In that respect, the production side of the model is essentially the same as the one presented in Rutherford and Tarr (2002). Entrepreneurial skills are modeled as exogenous endowments, which means that the number of intermediate firms cannot in the long run grow faster than the fixed supply of skills. Another important difference from most studies in the endogenous growth literature is that we present numerical simulations that allow us to focus on transitional effects rather than solely on analytically derived characterizations of the steady state. The demand side of the model comprises overlapping generations with perfect foresight along the lines of Auerbach and Kotlikoff (1987) and Altig,

\footnotetext{
${ }^{5}$ Markusen, Rutherford, and Tarr (2001) consider the effects of knowledge imports by presenting a model of expanding product varieties with both domestic and foreign varieties of intermediates.
} 
Auerbach, Kotlikoff, Smetters, and Walliser (2001). We now turn to a more detailed description of each of the model's building blocks.

\subsection{Consumer behavior}

Final consumption arises from overlapping generations of finitely-lived households. A household of generation $j$ enters the economy at age 20, retires when reaching age 60 , and is identified by the year $t$ in which it enters the economy. For $t=0,1,2, \ldots$, each household maximizes the utility of lifetime consumption subject to the budget constraint that the present value of lifetime consumption does not exceed the present value of income:

$$
\begin{gathered}
\max _{c_{j, t}} u\left(c_{j, t}\right)=\sum_{t=j}^{j+39}\left(\frac{1}{1+\rho}\right)^{t-j} \frac{c_{j, t}^{1-\theta}}{1-\theta}, \\
\text { s.t. } \quad \sum_{t=j}^{j+39} p_{t}^{Y} c_{j, t} \leq \sum_{t=j}^{j+39}\left(p_{t}^{L} \omega_{j, t}^{L}+p_{t}^{E} \omega_{j, t}^{E}\right)+p_{0}^{F} \bar{f}_{j, 0}+p_{0}^{K} \bar{k}_{j, 0},
\end{gathered}
$$

where $\rho$ is the utility discount rate, $1 / \theta$ is the intertemporal elasticity of substitution, $c_{j, t}$ is consumption of the final good, $\omega_{j, t}^{L}$ and $\omega_{j, t}^{E}$ are endowments of labor and entrepreneurial skills, $\bar{f}_{j, 0}$ and $\bar{k}_{j, 0}$ are the exogenously given initial holdings of knowledge capital and physical capital, and the $p$ 's are the corresponding present value prices. ${ }^{6}$ We normalize the world market price of final goods to unity in future value, but domestic prices may differ due to changes in the exchange rate, which would then be reflected in the domestic interest rate. Consequently, in present value terms, $p_{t}^{Y}=\prod_{s=1}^{t}\left(1+r_{s}\right)^{-1}$, where $r_{t}=p_{t-1}^{Y} / p_{t}^{Y}-1$ is the interest rate in period $t$ and where $p_{0}^{Y}$ is the numeraire.

Each generation is endowed with both labor and entrepreneurial skills. For simplicity, we assume that the time profile of these endowments is flat over the life cycle. Furthermore, the aggregate labor supply is constant, so $L_{t}=\sum_{j} \omega_{j, t}^{L}=L_{t}=\bar{L} \forall t$. Entrepreneurial skills, in contrast, are subject to exogenous growth, making this is the source of long-run economic development. In the baseline, each generations' endowment of entrepreneurial skills is higher than the previous generations' by a factor $g$ so $\sum_{j} \omega_{j, t}^{E}=\bar{E}_{t}=\bar{E}_{0}(1+g)^{t}$. It is against this that we compare the effects of a surge in the level of entrepreneurial capacity.

\footnotetext{
${ }^{6}$ Throughout the paper, we express all prices in present value prices relative to time $t=0$, and use bars to indicate quantity levels in the baseline.
} 


\subsection{Final good production}

In each year $t$, the production of the final good, $Y_{t}$, takes place under perfect competition using inputs of labor and differentiated intermediate inputs, $x_{i}$ :

$$
Y_{t}=\phi_{Y} \bar{L}^{1-\alpha} \sum_{i=1}^{N_{t}} x_{i, t}^{\alpha},
$$

where $\phi_{Y}=\alpha^{-\alpha}(1-\alpha)^{-(1-\alpha)}$ is a scaling parameter, $\alpha$ is the cost share of intermediate inputs, and $N_{t}$ is the number of intermediate firms at time $t$, which is proportional to the number of blueprints in the economy. The number of intermediate firms is taken as given in the production decision implying that there is constant return to scale from the producer perspective, while total factor productivity is increasing with $N_{t}$ overall.

With symmetric firms, each intermediate firm produces the same quantity $x_{i, t}=x_{t}$, and the model may therefore conveniently be formulated in terms of the total number of intermediates:

$$
Y_{t}=\phi_{Y} N_{t}^{1-\alpha} \bar{L}^{1-\alpha} X_{t}^{\alpha},
$$

where $X_{t}=N_{t} x_{t}$ is the aggregate output of intermediates. The aggregate level of labor endowments is constant at $\bar{L}$ and total input demands are given by

$$
\begin{aligned}
X_{t} & =N_{t}\left(\phi_{Y} \alpha \frac{p_{t}^{Y}}{p_{t}^{X}}\right)^{\frac{1}{1-\alpha}} \bar{L}, \\
\bar{L} & =(1-\alpha) \frac{p_{t}^{Y}}{p_{t}^{L}} Y_{t},
\end{aligned}
$$

where $p_{t}^{X}$ is the price of intermediates, and the price of final goods is given by

$$
p_{t}^{Y}=N_{t}^{\alpha-1}\left(p_{t}^{X}\right)^{\alpha}\left(p_{t}^{L}\right)^{1-\alpha} .
$$

\subsection{Intermediate goods production}

Firms produce intermediate output under monopolistic competition with variable costs resulting from inputs of final goods and physical capital. The symmetry assumption implies that all firms producing intermediates have the same technology, produce the same level of output, and charge the same price. Consequently, total output of intermediates may be expressed in terms of total inputs:

$$
X_{t}=\phi_{X} K_{t}^{\xi} D_{t}^{1-\xi}
$$


where $\phi_{X}=\alpha^{-1}(r+\delta)^{\xi} \xi^{-\xi}(1-\xi)^{-(1-\xi)}, r$ is the baseline interest rate, $\delta$ is the depreciation rate of physical capital, $\xi$ is the cost share of physical capital services, $K_{t}$ is the stock of physical capital, and $D_{t}$ are material inputs to the production of intermediates. The profit maximizing mark-up on the unit cost of production is $1 / \alpha$, so aggregate gross profit is $\Pi_{t}=(1-\alpha) p_{t}^{X} X_{t}$ and the market price of intermediates is

$$
p_{t}^{X}=\left(p_{t}^{R K}\right)^{\xi}\left(p_{t}^{Y}\right)^{1-\xi},
$$

where $p_{t}^{R K}$ is the price of physical capital services.

In addition to the variable cost of production, firms producing intermediates pay a fixed one-time fee for a blueprint, $p_{t}^{F}$, allowing the firm to operate in perpetuity. The total equity of such firms, i.e., the value of all intermediateproducing firms, is equal to the present value of future profits:

$$
V_{t}=N_{t} \sum_{s=t}^{\infty}(1-\alpha) p_{s}^{X} x_{s} .
$$

This amount, $V_{t}$, may reasonably be interpreted as the knowledge capital of the economy.

\subsection{Firm creation and capital accumulation}

Investment takes place under perfect competition and the two types of capital accumulate according to standard convention. In the case of knowledge capital, investments require inputs of final goods, $B_{t}$, and entrepreneurial skills, $E_{t}$ :

$$
F_{t+1}=F_{t}+\phi_{N} B_{t}^{\gamma} E_{t}^{1-\gamma}
$$

where $\phi_{N}=\gamma^{-\gamma}(1-\gamma)^{-(1-\gamma)}$ and $I_{t}^{F}=\phi_{N} B_{t}^{\gamma} E_{t}^{1-\gamma}$ is total investment in firm creation. We think of each new unit of knowledge capital as a blueprint with a price $p_{t}^{F}$, and normalize the number of intermediate-producing firms to unity in the benchmark so that $N_{t} \bar{F}_{0}=F_{t}$ meaning that the establishment of a new firm requires $\bar{F}_{0}$ blueprints. With free entry and exit among producers of intermediates, the value of knowledge capital, as expressed in (7), is on the margin equal to the cost of firm creation so $V_{t}=p_{t}^{F} F_{t}$. Competitive behavior among investors means that the price of a blueprint, $p_{t}^{F}$, is equal to the resale value plus the rate of return, $p_{t}^{R F}$ :

$$
p_{t}^{F}=p_{t+1}^{F}+p_{t}^{R F} .
$$


Here cost minimization implies ${ }^{7}$

$$
p_{t+1}^{F}=\left(p_{t}^{Y}\right)^{\gamma}\left(p_{t}^{E}\right)^{1-\gamma},
$$

where $p_{t}^{E}$ is the price of entrepreneurial skills and the return on a blueprint is the monopoly profit from a unit of knowledge capital so $p_{t}^{R F}=(1-\alpha) p_{t}^{X} X_{t} / F_{t}$.

Investment in physical capital only involves input of final goods and a constant depreciation rate $\delta$ applies:

$$
K_{t+1}=(1-\delta) K_{t}+I_{t}^{K}
$$

where $I_{t}^{K}$ is gross investment in physical capital. Competitive behavior implies that the price of physical capital is given by

$$
p_{t}^{K}=(1-\delta) p_{t+1}^{K}+(r+\delta) p_{t}^{R K}
$$

where $p_{t+1}^{K}=p_{t}^{Y}$, and $p_{t}^{R K}=\left(r_{t}+\delta\right) p_{t}^{Y} /(r+\delta)$. Here, to simplify the exposition, we have normalized the rental price of physical capital so $p_{t}^{R K} / p_{t}^{Y}$ is equal to unity in the baseline, where $r$ is the baseline interest rate. In a deterministic framework arbitrage between the two means of storing value implies that knowledge capital and physical capital earn the same rate of return measured in units of a common good.

\subsection{Market clearance}

Market clearance in the final goods market requires supply/demand balance at the aggregate level as well as consistency with individual household demand:

$$
Y_{t}=C_{t}+D_{t}+B_{t}+I_{t}^{K}+S_{t}
$$

where $\sum_{j} c_{j, t}=C_{t}$ is the aggregate consumption level and $S_{t}$ is the trade surplus. With the small open economy assumption, the absence of restrictions on trade or international capital mobility means that $p_{t}^{Y}$ is given and fixes the economy's interest rate at the rate $r$ that applies on the world market. When the economy cannot access international credit markets the domestic interest rate is endogenous and $S_{t}=0$.

\footnotetext{
${ }^{7}$ This assumes that an equilibrium always involves positive investment levels, which is the case for all the simulations under consideration. Corner solutions, in which (9) is replaced by an inequality exhibiting complementary slackness with $I_{t}^{F} \geq 0$ are, however, accommodated in our computational framework.
} 


\subsection{The steady state}

To characterize the steady state, consider a given steady state interest rate equal to $\tilde{r}$ so $p_{t}^{Y}=(1+\tilde{r})^{-t}$, which from the definition of $p_{t}^{R K}$ means that $p_{t}^{R K} / p_{t}^{Y}$ is constant. From (6) we get that also $p_{t}^{X} / p_{t}^{Y}$ is constant, and, consequently, from (2), (3), (4), (5), (8), and (11) we get $g_{X}=g_{N}, g_{\left(p^{L} / p^{Y}\right)}=g_{Y}$, $g_{N}=g_{\left(p^{L} / p^{Y}\right)}, g_{X}=g_{D}=g_{K}, g_{F}=g_{I^{F}}=g_{B}=g$, and $g_{K}=g_{I^{K}}$, where the $g$ 's indicate steady-state growth rates of the term in subscript. Since $g_{F}=g_{N}$ by definition, combining these equations shows that all these growth rates are the same and equal to $g$, the growth rate in entrepreneurial skills. Given these growth rates, the market clearing condition (13) implies that $g=g_{C}=g_{S}$ and hence we find that the steady-state growth rate of all components of production and consumption are exogenously given. ${ }^{8}$

To derive the steady-state value of knowledge capital, note that (2) and a constant $p_{t}^{X} / p_{t}^{Y}$ implies that the individual firms' output of intermediates is constant so $x_{t}=x$. From $(7)$, and $p_{t+i}^{X}=p_{t}^{X}(1+\tilde{r})^{-i}$ the total present value of knowledge capital at time $t$ is then given by

$$
V_{t}=N_{t} \sum_{s=t}^{\infty}(1-\alpha) p_{s}^{X} x=\frac{1+\tilde{r}}{\tilde{r}} \Pi_{t} .
$$

From $V_{t}=p_{t}^{F} F_{t}$ and $N_{t}=F_{t} / \bar{F}_{0}$ it follows that $p_{t}^{F} / p_{t}^{X}$ and $p_{t}^{F} / p_{t}^{Y}$ are constant. Finally, from (9) and the expressions for $p_{t+1}^{F}$ and $p_{t}^{R K}$ we conclude that $p_{t}^{E} / p_{t}^{Y}$ is also constant. This means that total household income from entrepreneurial skills grows at the rate $g$, just as is the case for labor income. Inspection of the various price definitions shows that all other future-value prices are constant.

That the long-run growth rate in this model is exogenous differs from the standard expanding product varieties endogenous growth framework in which long-run growth is not tied down by the level of endowments but may be affected by policy. The different outcome follows from our assumption that $\gamma<1$ so that investments in firm creation in (8) involve an input that is in fixed

\footnotetext{
${ }^{8}$ The model exhibits the same feature if we include exogenous growth in $L_{t}$. In that case $g_{N}=g$ as here, but the model would also involve several other (exogenous) steady-state growth rates. To keep the analysis transparent, we keep $L_{t}$ constant and focus on the engine of growth: effective increases in entrepreneurial capacity.
} 
supply. ${ }^{9}$ This implies diminishing returns in firm creation since an increase in demand for blueprints will drive up the price of entrepreneurial skills thereby ensuring that the ratio of skill endowments to the number of firms is constant in a steady state. ${ }^{10}$ Following Jones (1995), we label the model as one of "semi-endogenous" growth, reflecting that technological change is endogenous during a transition but exogenous in the long run.

\subsection{Calibration}

We calibrate the model by assuming that the economy is in an initial steady state where all production activities grow at the rate $g$, the trade surplus, $S_{t}$, is zero, and the interest rate is constant at $r$. To provide an initial benchmark, we construct a baseyear $(t=0)$ dataset that satisfies the requirements of a steady state, and we normalize $p_{t}^{L}$ and $p_{t}^{E}$ to unity in the baseyear so that $p_{0}^{Y}=p_{0}^{X}=1$ and $p_{0}^{F}=p_{0}^{K}=1+r$. In addition, we ensure that the aggregate data is consistent with the outcome of the household maximization problem.

The characteristics of the steady state, as outlined in the previous section, provide relationships between investment levels and capital earnings that need to be satisfied in the benchmark data. From (14), total capital income knowledge capital is $\bar{\Pi}_{0}=r \bar{F}_{0}$ where $\bar{F}_{0}=\bar{V}_{0} /(1+r)$ is the benchmark stock of knowledge capital with the term in the denominator correcting for differences in price levels due to the fact that investments require one year to mature. From (8), the steady state assumption also requires that benchmark investments in firm creation cover growth on the stock of firms so that $\bar{I}_{0}^{F}=g \bar{F}_{0}$. The steady-state conditions regarding the benchmark physical capital stock, $\bar{K}_{0}$, are derived in a similar way to those relating to knowledge capital except for differences due to the inclusion of a depreciation term. Here we get that total income from physical capital is given by $(r+\delta) \bar{K}_{0}$ and that investments are given by $\bar{I}_{0}^{K}=(g+\delta) \bar{K}_{0}$.

\footnotetext{
${ }^{9}$ In addition, we consider among others the case of an open economy with perfect international capital markets. In this situation the domestic interest rate is exogenous, which would tie down the steady-state growth rate also in the standard model.

${ }^{10}$ To provide a consistent basis for the small open economy assumption we implicitly assume that the growth rate abroad also is equal to $g$ so that the relative size of the domestic economy does not trend. The fact that the present model has $g$ as the exogenous longrun growth rate is therefore appealing as a change in the steady-state growth rate would ultimately become inconsistent with the small open economy assumption.
} 
To ensure that the aggregate data is consistent with the outcome of utility maximizing households, we follow the methodology laid out by Rasmussen and Rutherford (2002), which implies calibrating the utility discount rate $\rho$ so that $\sum_{j} \bar{f}_{j, 0}+\sum_{j} \bar{k}_{j, 0}=\bar{F}+\bar{K}$. For the numerical simulations presented in the following, we adopt the parameter values presented in Table A.1., and the corresponding social accounting matrix shown in Table A.2. This implies $\rho=0.003$ and the income/consumption profiles shown in Figure 1, where endowment income consists of income from sale of labor and entrepreneurial skills. ${ }^{11}$

Figure 1 about here

Given the flat profile of endowment income, the model implies a constant baseline growth rate of consumption over the life cycle. Households accumulate assets during middle age and then dissave when old, as predicted by the lifecycle view of savings. ${ }^{12}$ Since knowledge capital and physical capital earn the same net rate of return households are indifferent between the two types of assets. To assign values to $\bar{f}_{j, 0}$ and $\bar{k}_{j, 0}$ we therefore assume that all households hold the two asset types in the same proportion at all times in the initial steady state. $^{13}$

The numerical model is formulated over a 200-year horizon and solved in one-year intervals, thus capturing 40 overlapping generations at any point in time. The solution procedure involves imposing a number of terminal constraints on the model to ensure that the outcome approximates the infinite

\footnotetext{
${ }^{11}$ Consistency could also be achieved by setting $\rho$ exogenously and calibrating either $g$ or $r$. We choose to calibrate $\rho$ as we view this parameter as the most uncertain. The resulting value of $\rho=0.003$ is in any case similar to the value of 0.004 used in Altig, Auerbach, Kotlikoff, Smetters, and Walliser (2001) where this parameter is set exogenously.

${ }^{12}$ The calibrated consumption growth path is somewhat steep through the lifecycle. A more realistic consumption profile could be obtained by imposing a more probable humpshaped profile for effective labor endowments, as it is done in, e.g., Auerbach and Kotlikoff (1987). We abstain from doing so to maintain simplicity.

${ }^{13}$ This assumption is important as it determines how different age groups are exposed to capital gains and losses resulting from changing asset prices due to an unanticipated policy change.
} 
horizon equilibrium path to the new steady-state equilibrium (see Rasmussen and Rutherford (2002) for details). ${ }^{14}$

\section{Model results}

Based on the rapid growth in new firms, we think of the reform process in transition economies as closely related to the level of entrepreneurial capacity. Better opportunities for establishing and protecting property rights in these countries mean that entrepreneurs are more willing to undertake investments. Also, the greater integration into world markets that follows from market liberalization can reasonably be assumed to imply greater opportunities for dissemination of knowledge. In particular, entrepreneurs may more easily adopt foreign knowledge about how firm creation is most effectively carried out. The bottom line is that these countries have experienced a change of circumstances that have boosted firm creation, and we capture this effect in reduced form by a shock to the model that increases the overall level of entrepreneurial skills, $E_{t}=\sum_{j} \omega_{j, t}^{E}$. We then investigate the distributional consequences of how increases $\omega_{j, t}^{E}$ are distributed among the different generations.

Table 1 about here

Table 1 shows the proportion of workers in the Baltic countries employed in enterprises established since the transition process began around 1988, as reported by Antila and Ylöstalo (1999). Two features stand out. First, after just a single decade a very large part of the workforce is now employed in new firms. Second, workers in new firms tend to be young. These results are complemented by other figures also reported by Antila and Ylöstalo, which show that average salaries in the Baltic countries are substantially higher in new enterprises than they are in the rest of the economy, and that within new enterprises younger workers earn substantially higher wages than older workers

\footnotetext{
${ }^{14}$ The model is programmed in GAMS/MPSGE and solved with the GAMS/PATH algorithm (see Rutherford (1999) and Ferris and Munson (2000)), and it is available from the authors upon request.
} 
relative to what is the case in the rest of the economy. ${ }^{15}$ Estonia, which has been the most successful of the three transition economies, also presents the most extreme example. Here, average wages in new enterprises are about 30 percent higher than the rest of the economy, and within new enterprises the under 30-year-olds earn about 30 percent more than those over 50 while the two age groups earn about the same in the rest of the economy. All this points to a clear picture of developments that have favored younger workers.

One likely explanation for these developments is that younger workers have benefited by having a better match with the skills that are most valuable in the new business environment. Presumably, younger workers are more inclined, and perhaps more able, to attain the set of skills-ranging from computer skills to entrepreneurship-that have become especially valuable. Even if the ability to obtain such new skills is the same, older generations have a shorter remaining life span and are therefore may be reluctant to undertake the investment in acquiring these skills. ${ }^{16}$ While such considerations are probably true everywhere, they are especially important in transition economies where economic restructuring has suddenly introduced a wide disparity between the existing skill-base and the demands of the workplace.

To capture the relationship between the transition process, seen here as the forces accompanying an increase in firm creation, and the advantage of being young, we use the data in the last column of Table 1 to formulate the BALTIC scenario. In this transition path generations who enter the economy in year 0 or anytime thereafter experience a proportional increase of their entrepreneurial endowment, $\omega_{j, t}^{E}$, by $\beta$ so that $E_{t}=(1+\beta) \bar{E}_{t}$ for $t \geq 39$. Generations with ages 21 to 30 in year 0 , in contrast, experience a smaller increase of $0.80 \beta$; those between ages 40 and 31 experience an increase of $0.62 \beta$; those between ages 50 and 41 experience an increase of $0.46 \beta$; and those older than 51 experience no gain at all. This implies that in year $t=10$ the increase in skill endowments accruing to the different generations will be distributed in accordance with the Baltic age profile of workers in new firms. As such this is a simplified way of reflecting the observed benefits of being young in a model that does

\footnotetext{
${ }^{15}$ In this data, Latvia is an exception in that the age profile of wages in new enterprises is not significantly different from that in the rest of the economy, although average salaries in new enterprises are higher also in this country.

${ }^{16}$ Friedberg (2002) finds such an effect in acquisition of computer skills in the U.S. where evidence suggests that computer use is associated with a lower probability of retirement.
} 
not distinguish between different types of skills or labor. In our numerical calculations we investigate transition paths associated with $\beta=0.1$, i.e., an increase in the long-run level of entrepreneurial skills of 10 percent.

Obviously, this approach represents only one of many possible interpretations of the underlying causes for the developments summarized by the data in Table 1. For example, the relative disadvantage experienced by the old may simply reflect that uncompetitive wage setting in favor of the old is more prevalent in old enterprises. To put perspective on the importance of the specific details of the shock that is imposed on the model, we consider two alternative scenarios: UNIFORM and YOUNG that bracket the range of possible allocations of skill increases between the young and the old. In the UNIFORM scenario all generations share the same proportional increase in entrepreneurial endowments. In the YOUNG scenario only new generations, i.e., those entering the economy after year 0 , benefit. These two extreme cases would correspond to a situation where acquisition of entrepreneurial skills is entirely determined by an investment decision, and where the fixed cost of skill acquisition in one case is so small that all generations undertake the investment, while the cost in the other case is so large that only new generations do. ${ }^{17}$

Since neither of the three shocks change the steady-state growth rate of $E_{t}$, the resulting steady state may be compared to the baseline by noting that this is equivalent to a simple re-scaling of the units in the model so that $p_{t}^{L} / p_{t}^{E}$ increases by $\beta$. Consequently, all components of household income increase by the same amount and there is no change in the steady-state interest rate. Using the logic of Section 2.6 we know that all aggregate production activities, as well as $p_{t}^{L} / p_{t}^{Y}$, will continue to have a steady state growth rate equal to $g$, while $p_{t}^{X} / p_{t}^{Y}$ and all other relative prices except those relating to $p_{t}^{L}$ return to the baseline level. As a result, aggregate consumption and all output level will also increase by $\beta$, and from (13), this implies that the trade balance will return to zero. The different shocks thus all have the same steady state impact, but, as we show in the next section, the transitional dynamics will differ markedly.

\footnotetext{
${ }^{17}$ With the Cobb Douglas technology in (8), the case where all generations benefit so $E_{t}=(1+\beta) \bar{E}_{t}$ for $\forall t \geq 0$ is equivalent to a situation with a one-time increase in the total factor productivity of firm creation. This situation may also be interpreted as one where better property rights make resources used for firm creation more productive.
} 


\subsection{Transitional dynamics}

When the model is exposed to a shock it will undergo a transition to a new steady state. Investments in physical capital accumulation only require inputs of final goods, which are traded on the world market. With no restrictions on the trade balance, the small open economy assumption means that the supply of inputs to physical capital investments is perfectly elastic. Consequently, the economy would adjust immediately to a shock that only affects the physical capital stock and the interest rate would remain constant. In contrast, the shocks that we consider here involve the level of entrepreneurial capacity, which impacts on the steady-state number of firms. Because one of the inputs to investment in firm creation, entrepreneurial skills, is in fixed supply costminimization dictates that investments will only gradually bring the number of firms to the new steady-state level even if the interest rate is unaffected.

The absence of credit markets has important implications for transitional dynamics. A binding restriction on the level of the trade deficit means that the economy cannot rely on imports to immediately adjust to a shock, but would adjust its exchange rate to match imports with exports. In such a situation, an increase in investments in firm creation following from a shock to $E_{t}$ will be spread out over a number of years and the domestic interest rate changes over the transition. ${ }^{18}$ Eventually, however, the model will reach the new steady state where the interest rate has returned to $r$ and all relative prices, except those relating to $p_{t}^{L}$, will have returned to the initial level. Intuitively, to the extent that the increase in potential income in transition economies is related to an increase in stocks of knowledge or physical capital that are costly to build up too rapidly, it makes sense that it does not happen immediately.

\subsubsection{Perfect capital mobility}

We first consider a situation where there are no restrictions on the economy's ability to borrow abroad to finance a temporary trade deficit other than that the present value of exports must equal the present value of imports over the infinite horizon. Figure 2 shows the impact over the first part of the transition following from the shock to $E_{t}$. This situation implies an initial

\footnotetext{
${ }^{18} \mathrm{An}$ extreme example of such a trade restriction would be to allow no trade whatsoever, in which case the model would simply be one of a closed economy.
} 
deficit as investors exploit the opportunity to finance part of the initial increase of investments in firm creation on the world capital market.

Figure 2 about here

Since the interest rate and the price of final goods are in this setting given by the level on the world market, $p_{t}^{X}$ and $p_{t}^{Y}$ are both fixed at the baseline level. From (2) we then get that $x_{t}=x$, and we can follow the approach of Section 2.6 to conclude that $p_{t}^{F}$ and $p_{t}^{E}$ also are fixed at the baseline level. This implies that all prices are unchanged except $p_{t}^{L}$, which by (3) grows over time at the same rate as output, $Y_{t}$, where also $g_{Y_{t}}=g_{N_{t}}$. The evolution in the number of firms, $N_{t}$, is consequently the driving force of the transitional dynamics. Profit maximization means that investments in firm creation are carried out up to the point where the cost, as implied by (9), is equal to income as defined by (7). Since there is no depreciation of knowledge capital and both input and output prices of investments in firm creation are unchanged, it follows from (8) that the level of these investments is proportional to $E_{t}$.

Consider first the UNIFORM scenario in which all generations benefit from the productivity increase. Here $E_{t}=(1+\beta) \bar{E}_{t} \forall t \geq 0$ and $I_{t}^{F}$ jumps immediately to the new steady state level, i.e., an increase by $\beta$. We can then quantify the speed of the transition by noting that the actual number of firms, $N_{t}$, is given by

$$
N_{t} \bar{F}_{0}=\bar{I}_{0}^{F} / g+\sum_{s=0}^{t-1}(1+\beta) \bar{I}_{0}^{F}(1+g)^{s}
$$

which differs from the steady-state level, $N_{t}^{*}$, given by

$$
N_{t}^{*} \bar{F}_{0}=(1+\beta) \bar{I}_{0}^{F} / g+\sum_{s=0}^{t-1}(1+\beta) \bar{I}_{0}^{F}(1+g)^{s}=(1+\beta) \bar{I}_{0}^{F}(1+g)^{t} / g .
$$

Defining the speed of transition as the rate of change in $\mu_{t}$, where $\mu_{t}=$ $\left(N_{t}^{*}-N_{t}\right) / N_{t}^{*}$ is the fraction of the remaining difference from the steady state number of firms that vanishes in year $t$, we get $\mu_{t}=(1+g)^{-t} \beta /(1+\beta)$. In other words, the speed of the transition is constant and equal to $g$. With a 
2 percent annual growth rate in the steady state, this means that it takes 35 years for the number of firms to reach half of the long-run increase. In the BALTIC and YOUNG scenarios $E_{t}$ only approaches the new steady state level gradually and does not reach $(1+\beta) \bar{E}_{t}$ until all generations in the economy are of the type that have benefited from the full productivity increase, which happens in year 39. Consequently, investments are initially lower and $N_{t}$, and hence also $p_{t}^{L}$ and $Y_{t}$, take longer to reach the new steady state level.

With all prices except $p_{t}^{L}$ unchanged, the continuous increase in the number of firms means that all generations benefit from the shock. Every generation entering the economy after year 0 , as well as those of the current generations that are assumed to benefit from higher endowment levels, experience a level increase in earnings from the sale of entrepreneurial skills. Over time each generation that lives past year 0 also experiences increasing labor income due to the rise in $p_{t}^{L}$. This produces the welfare gains shown in Panel A, where the equivalent variation ultimately levels off at 10 percent corresponding to the long-run increase in household income. ${ }^{19,20}$

With all generations experiencing an increase in life-cycle income, the shock causes a jump in aggregate consumption, $C_{t}$. Output, $Y_{t}$, on the other hand, is only growing gradually at the rate $g_{t}^{N}$, which, as shown in Panel B, means a large initial trade deficit when all generations experience the increase in entrepreneurial skill earnings, but a smaller trade deficit when household income is increasing more gradually as is the case when only new generations experience the increase in entrepreneurial skill earnings. Subsequently, the trade balance improves as household income grows at a slower rate than output, with the ratios $C_{t} / Y_{t}$ showing the inverse relationships of those appearing in Panel B. After a period with deficits, the trade balance thus becomes positive, allowing debt incurred during the initial part of the transition to be paid back, and eventually the balance returns to zero.

\footnotetext{
${ }^{19}$ For the initial population the reported welfare changes relate to remaining life time utility.

${ }^{20}$ To evaluate the significance of the OLG demand system, it is useful to compare these results to those arising with an Ramsey-type characterization of household demand. Assuming a single infinitely-lived agent with an utility discount rate equal to $(1+r) /(1+g)^{\theta}-1$ and otherwise maintaining the above parameterization produces the same baseline equilibrium. Here a 10 percent increase in this agents endowment of entrepreneurial skills results in an equivalent variation of 3.8 percent.
} 


\subsubsection{Imperfect capital mobility}

We now consider a situation where trade is required to balance in every year, i.e., $S_{t}=0$, and Figure 3 shows the results. As shown above, the long run impact is the same as in the situation without any restrictions on the trade balance. In contrast to that situation, however, $p_{t}^{Y}$ is no longer declining with a constant interest rate so all relative prices, not just those relating to $p_{t}^{L}$, are changing during the transition. Without the possibility of using international capital markets to finance a temporary trade deficit, the immediate increase in investments in firm creation is smaller than before, implying a slower transition. As shown in Panel A, in the UNIFORM scenario it takes 40 years for the number of firms to reach half of the steady state increase, and, at the other extreme in the YOUNG scenario, the same adjustment takes almost 60 years. Now the initial increase in investments requires households to forego consumption so that $C_{t} / Y_{t}$ must fall rather than increase as it did in the previous case. From Panel $\mathrm{B}$ we see that these ratios are in all cases initially decreasing, reflecting gradually rising investment ratios. This contrasts to the situation without the restriction on the trade balance where the impact on the $C_{t} / Y_{t}$ ratio was positive in the first part of the transition.

Figure 3 about here

The changes in investment levels are accompanied by the developments in the relative prices shown in Panels C and D. From (8) and (10) we get that $E_{t}=(1-\gamma)\left(p_{t}^{Y} / p_{t}^{E}\right)^{\gamma} I_{t}^{F}$. Hence, because the increase in entrepreneurial capacity is not offset by a correspondingly large jump in investments there is an initial reduction in $p_{t}^{E} / p_{t}^{Y}$, where, in each of the three scenarios, the magnitude of the initial decline reflects the magnitude of the increase in $E_{t}$ and is less than $(1+\beta)$. In subsequent years, the decline is in all cases reversed as $I_{t}^{F}$ rises. The effect on income is thus positive for generations that experience the full increase in skills but negative for those who are unaffected. The relative price of labor, $p_{t}^{L} / p_{t}^{Y}$, like that of entrepreneurial skills, is also lower than in the case with perfect capital mobility reflecting the smaller number of intermediateproducing firms. Consequently, total household income from these two sources is growing more slowly than before. 
As shown in Panel E, the shocks have a positive impact on the interest rate, which reflects the increasing demand for investments. In the YOUNG scenario the interest rate is falling for the first few years. This is the result of the negative effect on income of the decline in $p_{t}^{E} / p_{t}^{Y}$ for generations living in the initial years, which causes an increase in the supply of savings that more than offsets the effect of increased investments. Inspecting (1) we note that the expression for total present value income appearing on the r.h.s. of the budget constraint may be rewritten as

$$
\sum_{t=j}^{j+A} \prod_{s=1}^{t}\left(1+r_{s}\right)^{-1}\left(\frac{p_{t}^{L}}{p_{t}^{Y}} \omega_{j, t}^{L}+\frac{p_{t}^{E}}{p_{t}^{Y}} \omega_{j, t}^{E}\right)+p_{0}^{F} \bar{f}_{j, 0}+p_{0}^{K} \bar{k}_{j, 0} .
$$

This expression allows us to distinguish income changes due to the changes in future value prices from those due to changes in the interest rate. The mostly positive impact on interest rates tends to be welfare-worsening for the young who, as seen from Figure 1, are net borrowers, while the impact is positive for the old who are net lenders.

The final source of income changes for generations living in year 0 is a change in $p_{0}^{F}$ and $p_{0}^{K}$, i.e. changes in the value of assets held at the time of the shock. From (5) and cost minimizing behavior we get that

$$
X_{t}=\frac{(r+\delta) K_{t}}{\alpha \xi}\left[\frac{p_{t}^{X}}{p_{t}^{Y}}\right]^{\frac{1-\xi}{\xi}}
$$

Substituting this expression into (2) and noting that $K_{0}, N_{0}$, and $p_{0}^{Y}$ (the numeraire) are all unchanged from the benchmark, we get that also $p_{0}^{X}$ and hence $X_{0}$ are unchanged. Equation (6) implies that $p_{t}^{X} / p_{t}^{Y}=\left(p_{t}^{R K} / p_{t}^{Y}\right)^{\xi}$ so that $p_{0}^{R K}$ is also unaffected by the shock. From (12) and $p_{t+1}^{K}=p_{t}^{Y}$ this means that the same is true for $p_{0}^{K}$. The only welfare effect on account of an initial change in asset values is therefore the change in $p_{0}^{F}$. Since $p_{t}^{R F}=$ $(1-\alpha) p_{t}^{X} X_{t} / F_{t}$ the shock has no effect on $p_{0}^{R F}$, and from (9) and $p_{t+1}^{F}=$ $\left(p_{t}^{Y}\right)^{\gamma}\left(p_{t}^{E}\right)^{1-\gamma}$ we then get that the change in the price of knowledge capital is given by $\triangle p_{0}^{F}=\left(p_{0}^{E}\right)^{1-\gamma}-1$. Consequently, the first period reduction in the price of entrepreneurial skills is followed by a somewhat smaller reduction in the price of knowledge capital. In effect, a reduction in the cost of innovation causes a fall in the unit value of existing knowledge, which imposes capital losses on older generations. 
The changes in incomes of the different generations are reflected in the welfare changes shown in Panel F. The simulations show that in all scenarios the change in income of the oldest generation due to the reduction in $p_{0}^{F}$ is of an order of magnitude greater than income changes due to other sources reflecting that older generations benefit little from rising wages and that the change in interest rates is small. Consequently, the oldest generation in all cases ends up with the largest welfare loss. On the other hand, the youngest generations living in year 0 all experience a welfare gain. These generations have small asset holdings, and as a result they are not much affected by the decline in $p_{0}^{F}$ and they also benefit more by living further into the years with rising wages. ${ }^{21}$

The negative impact of capital losses is particularly great in the UNIFORM scenario since this case also implies the greatest increase in $E_{0}$. Here, the oldest generation experiences a welfare loss of almost 1 percent, i.e. nearly 10 percent of the long run increase in welfare, and losses apply to all households older than 49 years of age. At the other extreme, in the YOUNG scenarios (when only new generations benefit) capital losses are smaller, but here the effect on entrepreneurial skill earnings is increasingly negative so that the welfare loss is smaller initially but extends to all households older than 37 . In the intermediate case based on the Baltic experience the cut-off age is 46, which means that 35 percent of the initial population becomes worse off.

\subsection{Sensitivity analysis}

Table 2 shows the implications of the productivity shock with alternative parameter values in the case with yearly trade balance restrictions. Using a lower value of the intertemporal elasticity of substitution, $1 / \theta$, of 0.4 does not affect aggregate quantities in the baseline, but implies that households desire a higher degree of consumption smoothing. Consequently, equivalent variations decline during the transition, as households are more adverse to the changing relative prices that follow from the shock. The negative welfare effect increases the share of the initial population that experiences a welfare loss.

\footnotetext{
${ }^{21}$ In this case, the Ramsey-type characterization of household demand results in an equivalent variation of 3.2 percent.
} 
Table 2 about here

Raising the value of $\alpha$ increases $\bar{X}_{t}$ for given $\bar{Y}_{t}$ but reduces the markup factor so the overall effect on $\bar{F}_{t}$, and on $\bar{E}_{t}$ via (8) and $\bar{I}_{t}^{F}=g \bar{F}_{t}$, is ambiguous. With $\alpha=0.66$ the effect is positive and households thus become more exposed to the declines in $p_{0}^{F}$ and $p_{t}^{E} / p_{t}^{Y}$. Working in the opposite direction, a larger $\alpha$ means a reduction in $\bar{F}_{t} / \bar{K}_{t}$ so that the shock to $\bar{E}_{t}$ has a smaller impact on the interest rate, which means a smaller decline in these prices. In the case where all generations share in the full increase in skills the net effect is that capital losses increase and welfare losses extend to a greater share of the population, while the reverse outcome occurs when only new generations benefit.

Reducing the baseline interest rate increases the stock of total assets for given asset earnings, which in turn increases $\bar{I}_{t}^{F}$ and the relative importance of entrepreneurial skill earnings in total income. Consequently, initial generations experience greater capital losses due to the decline in $p_{0}^{F}$ and the share of the initial population that becomes worse off increases. Using a lower value for $\gamma$ means that investments in firm creation increase faster as the relative importance of $E_{t}$ in (8) increases. This means a faster transition and a decline in the share of the initial population that becomes worse off. The remaining model parameters, $g, \delta$, and $\xi$ are found to have very little impact on the profile of welfare changes.

The results of the sensitivity analysis show that the parameters in the model affect the welfare changes experienced by the initial population in different ways. In all the considered cases, however, older generations suffer a welfare loss and the fraction of the initial population that becomes worse off is greatest when only new generations benefit from the productivity increase. As seen from Table 2, the result that a significant proportion of the initial population becomes worse off is robust to changes in model parameters.

The assumption that all ages hold the two asset types in the same proportion along the baseline is important for the distribution of capital losses discussed in the previous section. We therefore consider an alternative parameterization in which the share of physical capital in total assets increases over the life cycle, so that the oldest generation only holds physical capital while younger cohorts hold a disproportionate share of knowledge capital. Each 
generation then has a short position in physical capital holdings for approximately the first half of the life cycle. ${ }^{22}$ The decline in $p_{0}^{F}$ is the major source for the welfare losses of older cohorts, so this alternative formulation reduces the welfare losses experienced by the old by shifting them to the young, which causes the proportion of the initial population that becomes worse off to decline. When only new generations experience an increase in entrepreneurial skills, the alternative formulation increases initial holdings of knowledge capital of the pivotal generations around ages 30-40 in year zero, which causes an increase in the proportion of the initial population, which is adversely affected.

\section{Concluding remarks}

The transition process from command to market economy in Central and Eastern European countries has been characterized not only by a rapid increase in private sector economic activity, but typically also by worsening welfare for older generations. In this paper we have presented an overlapping generations model, augmented by endogenous growth operating through expanding product varieties, which is capable of generating these two "stylized facts".

From a methodological perspective, we are not aware of any similar attempt to formalize the rise in private business formation in the context of transition economies. Indeed, the model presented in this paper is notable because a conventional approach with constant returns to scale would fail to account for the substantial increase in total factor productivity that has been experienced by most transition economies. Also, we believe that the application of overlapping generations of intertemporally optimizing households represents a novelty in the study of the transition process. More importantly, the combination of endogenous technological change and an OLG demand system within a unified

\footnotetext{
${ }^{22}$ The specific formula used to allocate asset holdings is here given by $\mu_{a}=$ $\lambda \sqrt{39-a} \sum_{a} \bar{m}_{a} / \sum_{a} \bar{m}_{a} \sqrt{39-a}$, where $\mu_{a}$ is the proportion of total baseline assets held as knowledge capital at age $a, \bar{m}_{a}$ is total asset holdings by age, and $\lambda=\bar{F}_{t} /\left(\bar{F}_{t}+\bar{K}_{t}\right)$ is the proportion of knowledge capital in total assets for the economy as a whole. A formulation that further reduces holdings of knowledge capital by the oldest generations, e.g., by replacing the square root terms in the above expression by a power greater than one half, can produce the outcome that no generations experience a welfare loss in the UNIFORM scenario. The BALTIC and Young scenarios result in welfare losses for some generations no matter what power is used.
} 
analytical framework seems to capture two crucial elements of the transition process.

From a policy perspective the conclusion of the paper is quite stark. Indeed, while market reforms are widely regarded as necessary for the creation of prosperity in the medium-to-longer term, they are very likely to be voted down in a "democratic referendum". In fact, in some scenarios shown in the paper, more than half of the working age population is made worse off by windfall gains from market liberalization that increase long-run consumption possibilities. This outcome is possible because an increase in the economy's capacity to generate new knowledge is likely to reduce the value of existing knowledge, which inflicts capital losses on the old. As a result, there is a distinct possibility that the outcome of a democratic process would be a vote against market liberalization, despite its long-run benefits. ${ }^{23}$ Thus, the most likely obstacle to market reforms emerges from an intergenerational conflict in objectives: older generations who bear the burden without reaping the gains are likely to oppose reform. This may also help explain the apparent reality of life in transition economies where market-oriented reforms have often been slow to be implemented. This is an interesting property of the model, not least since many observers seem to have been surprised by the fact that the transition takes so long time.

In future work we plan to extend the model in several directions. For example, while economic growth in the current version of the model is driven by entrepreneurial activity, it would be interesting to allow for endogenous skill (human capital) formation. Also, as a successful implementation of market reforms would typically require a careful balance between both inter- and intragenerational fairness, we would like to consider a model encompassing several different socioeconomic groups within each generation.

\section{References}

Aghion, P., And S. Commander (1999): "On the Dynamics of Inequality in the Transition," Economics of Transition, 7(2), 275-298.

\footnotetext{
${ }^{23}$ Jensen and Rutherford (2002) offer a similar political economy explanation why public debt reduction would almost surely be voted down in a referendum, even though it would most likely be beneficial from a welfare perspective.
} 
Altig, D., A. Auerbach, L. Kotlikoff, K. Smetters, and J. Walliser (2001): "Simulating Fundamental Tax Reform in the United States," American Economic Review, 91(3), 574-595.

Altonji, J., F. Hayashi, and L. Kotlikoff (1992): "Is the Extended Family Altruistically Linked? Direct Tests Using Micro Data," American Economic Review, $82,1177-1198$.

(1997): "Parental Altruism and Inter Vivos Transfers: Theory and Evidence," Journal of Political Economy, 105, 1121-1166.

Antila, J., And P. Ylöstalo (1999): Working Life Barometer in the Baltic Countries. Finish Ministry of Labor, Helsinki.

Auerbach, A. J., And L. J. Kotlikoff (1987): Dynamic Fiscal Policy. Cambridge University Press, Cambridge, MA.

Barro, R. J., And X. Sala-I-Martin (1995): Economic Growth. McGraw-Hill, New York, NY.

Ferris, M. C., And T. S. Munson (2000): GAMS/PATH User Guide Version 4.3GAMS Development Corporporation.

Fischer, S., And R. Sahay (2001): "The Transition Economies After Ten Years," in Transition and Growth in Post-Communist Countries: The Ten-Year Experience, ed. by L. T. Orlowski. Edward Elgar, Cheltenham.

Fougère, M., And M. Mérette (2000): "Population Aging, Intergenerational Equity, and Growth: Analysis with an Endogenous Growth Overlapping Generations Model," in Using Dynamic General Equilibrium Models for Policy Analysis, ed. by G. W. Harrison, S. E. H. Jensen, L. H. Pedersen, and T. F. Rutherford. North-Holland, Amsterdam.

FriedberG, L. (2002): "The Impact of Technological Change on Older Workers: Evidence from Data on Computer Use," Industrial and Labor Relations Review, to appear.

Jensen, S. E. H., And T. F. Rutherford (2002): "Distributional Effects of Fiscal Consolidation," Scandinavian Journal of Economics, 104(3), 471-493.

Jones, C. I. (1995): "R\&D-Based Models of Economic Growth," Journal of Political Economy, 103(4), 759-784.

Keane, M. P., and E. S. Prasad (2002): "Inequality, Transfers and Growth: New Evidence from the Economic Transition in Poland," Review of Economics and Statistics, to appear. 
Markusen, J., T. F. Rutherford, and D. G. Tarr (2001): "Foreign Direct Investments in Services and the Domestic Market for Expertise," NBER WP 7700, National Bureau of Economic Research, Cambridge, MA.

McMillan, J., And C. Woodruff (2002): "The Central Role of Entrepreneurs in Transition Economies," Journal of Economic Perspectives, 16, 153-170.

Rasmussen, T. N., And T. F. Rutherford (2002): "Modeling Overlapping Generations in a Complementarity Format," Journal of Economic Dynamics and Control, to appear.

Romer, P. M. (1987): "Growth Based on Increasing Returns Due to Specialization," American Economic Review, Papers and Proceedings, 77(2), 56-62.

(1990): "Endogenous Technological Change," Journal of Political Economy, 98(5), S71-S102.

Rutherford, T. F. (1999): "Applied General Equilibrium Modeling with MPSGE as a GAMS Subsystem: An Overview of the Modeling Framework and Syntax," Computational Economics, 14, 1-46.

Rutherford, T. F., And D. TARr (2002): "Trade Liberalization, Product Variety and Growth in a Small Open Economy: A Quantitative Assesment," Journal of International Economics, 56, 247-272. 


\section{Appendix}

Table A.1. Central Parameter Values

\begin{tabular}{lll}
\hline$r$ & Baseline interest rate & 0.05 \\
$g$ & Baseline growth rate & 0.02 \\
$\delta$ & Capital depreciation rate & 0.10 \\
$1 / \theta$ & Intertemporal elasticity of substitution & 0.80 \\
$\alpha$ & Intermediates cost share in final good production & 0.25 \\
$\xi$ & Capital cost share in intermediate good production & 0.33 \\
$\gamma$ & Final goods cost share in firm creation & 0.33 \\
\hline
\end{tabular}

Table A.2. Benchmark Social Accounting Matrix

\begin{tabular}{|c|c|c|c|c|c|c|c|c|c|c|}
\hline & \multicolumn{2}{|c|}{ Goods } & \multicolumn{2}{|c|}{ Sectors } & \multicolumn{4}{|c|}{ Factors } & \multicolumn{2}{|c|}{ Institutions } \\
\hline & $\mathrm{Y}$ & $\bar{X}$ & $\mathrm{Y}$ & $\mathrm{X}$ & $\bar{L}$ & $\bar{E}$ & $\mathrm{~K}$ & $\mathrm{~F}$ & $\mathrm{C}$ & $\mathrm{I}$ \\
\hline $\mathrm{Y}$ & & & & 4.2 & & & & & 91.7 & 4.1 \\
\hline $\mathrm{X}$ & & & 25 & & & & & & & \\
\hline $\mathrm{Y}$ & 100 & & & & & & & & & \\
\hline $\mathrm{X}$ & & 25 & & & & & & & & \\
\hline $\mathrm{L}$ & & & 75 & & & & & & & \\
\hline $\mathrm{E}$ & & & & & & & & & & 5.0 \\
\hline $\mathrm{K}$ & & & & 2.1 & & & & & & \\
\hline $\mathrm{F}$ & & & & 18.8 & & & & & & \\
\hline $\mathrm{C}$ & & & & & 75 & 5.0 & 2.1 & 18.8 & & \\
\hline I & & & & & & & & & 9.2 & \\
\hline
\end{tabular}

Notes: Values scaled so final good output $=100$. Columns represent expenditures and rows represent receipts. We assume that there are no imports or exports in the benchmark. 
Table 1. Proportion of a given age group working in enterprises established after $1988(\%)^{a}$

\begin{tabular}{lccccc}
\hline & \multicolumn{3}{c}{ Level } & \multirow{2}{*}{$\begin{array}{c}\text { Baltics } \\
\text { Age }\end{array}$} & Estoniative \\
to & Latvia & Lithuania & Baltics $^{b}$ & \\
Under 30 & 45 & 54 & 44 & 48 & 100 \\
$30-39$ & 40 & 39 & 36 & 38 & 80 \\
$40-49$ & 32 & 33 & 23 & 29 & 62 \\
Over 50 & 29 & 20 & 17 & 22 & 46 \\
Average & 37 & 37 & 30 & 34 & 72 \\
\hline
\end{tabular}

Source: Antila and Ylöstalo (1999) and authors' own calculations. ${ }^{a} 1998$ share of employed between ages 16 and $64 .{ }^{b}$ Average of the three countries.

Table 2. Share of initial population that experiences a welfare loss (\%)

\begin{tabular}{lccc}
\hline & \multicolumn{3}{c}{ Scenario } \\
\cline { 2 - 4 } & UNIFORM & BALTIC & YOUNG \\
\hline Base case & 27.5 & 35.0 & 57.5 \\
$1 / \theta=0.4$ & 35.0 & 42.5 & 62.5 \\
$\alpha=0.66$ & 32.5 & 37.5 & 55.0 \\
$r=0.04$ & 30.0 & 37.5 & 60.0 \\
$\gamma=0.1$ & 25.0 & 32.5 & 55.0 \\
Alternative distribution of initial assets & 17.5 & 32.5 & 60.0 \\
\hline
\end{tabular}

Notes: Assumes that international trade is balanced in each year. The base case involves $1 / \theta=0.8, \alpha=0.25, r=0.05$, and $\gamma=0.33$. 
Figure 1: Baseline income and consumption profiles

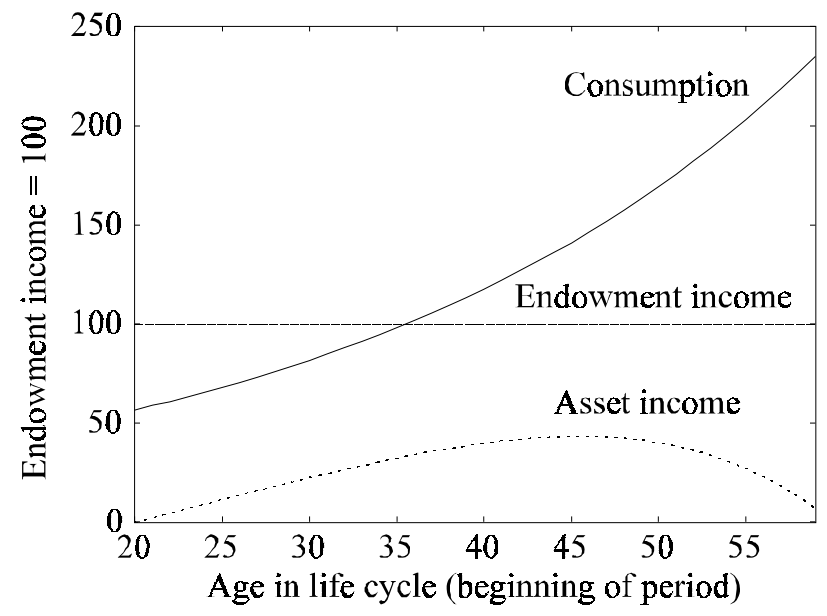


Figure 2: Impact of an increase in the entrepreneurial skills of select generations. International trade balanced intertemporally over the infinite horizon.

A. Welfare changes

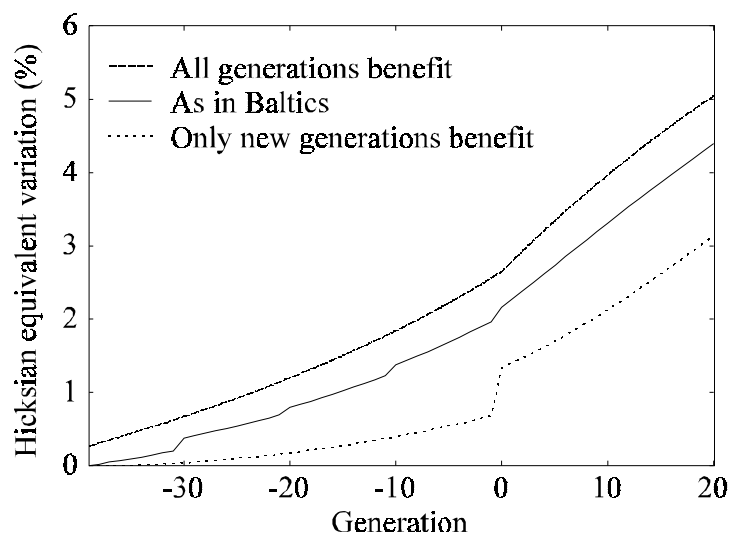

B. Trade balance

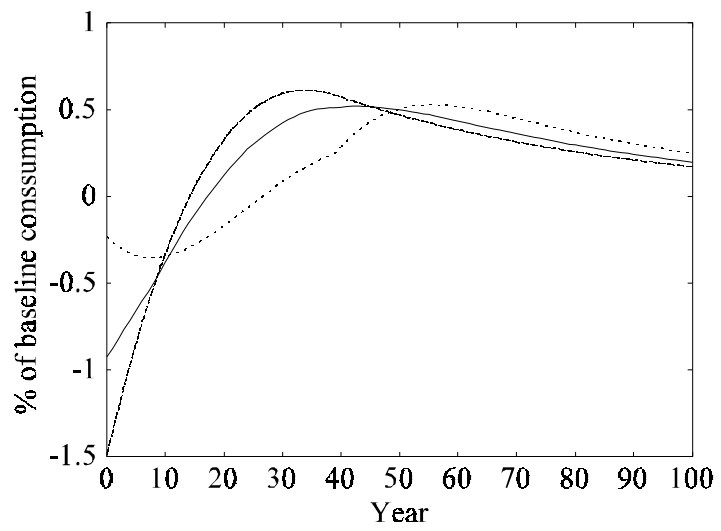


Figure 3: I mpact of an increase in the entrepreneurial skills of select generations. International trade balanced in each year.

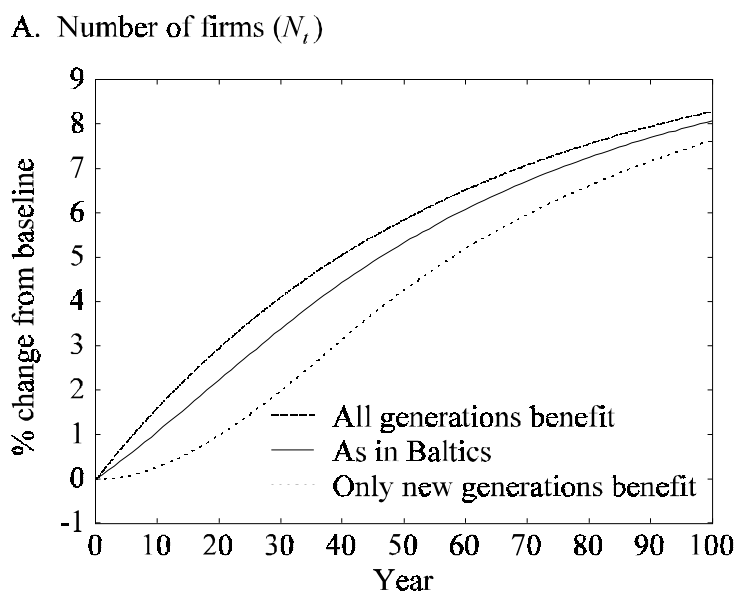

C. Price of entrepreneurial labor $\left(p_{t}^{E} / p_{t}^{Y}\right)$

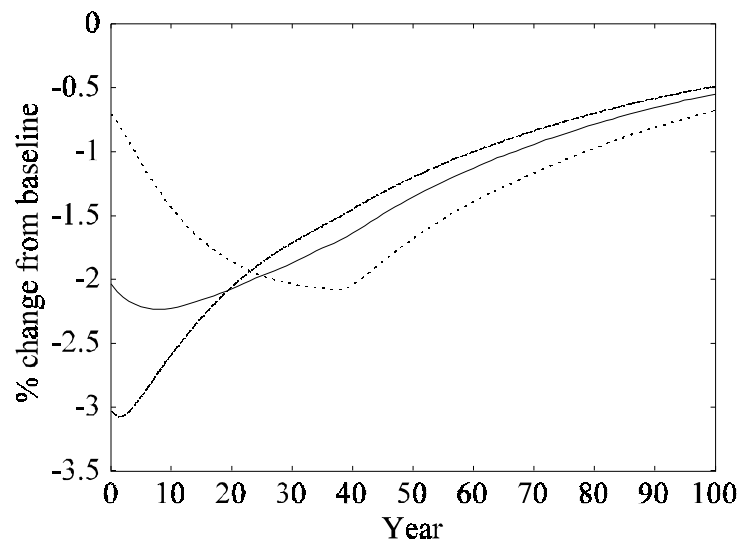

E. Interest rate $\left(r_{t}\right)$

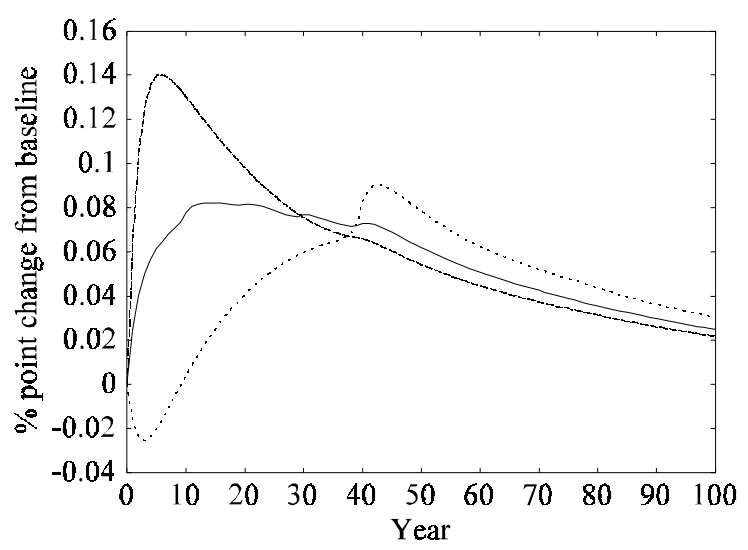

B. Consumption output ratio $\left(C_{t} / Y_{t}\right)$

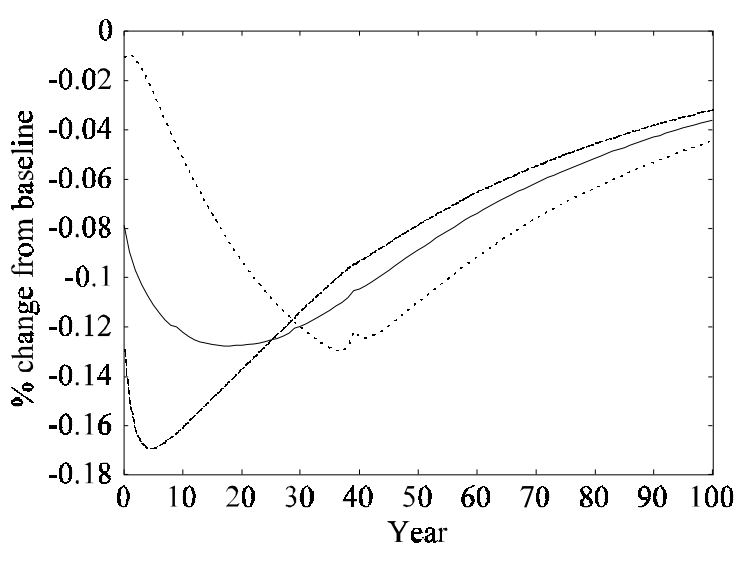

D. Price of ordinary labor $\left(p_{t}{ }^{L} / p_{t}{ }^{Y}\right)$

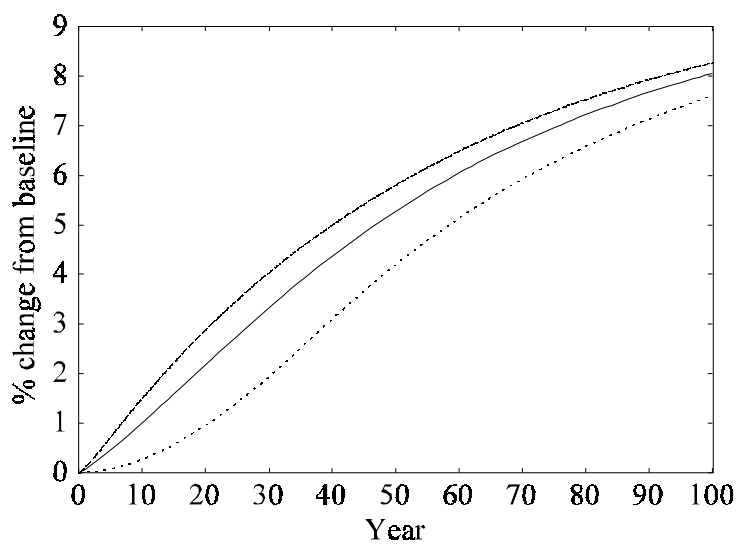

F. Welfare changes

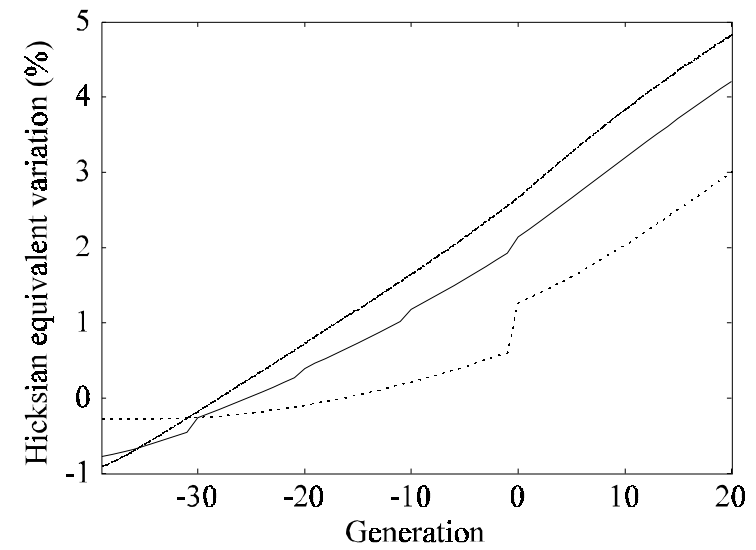

